\title{
Aging Male Spontaneously Hypertensive Rat as an Animal Model for the Evaluation of the Interplay between Contrast-Induced Acute Kidney Injury and Cardiorenal Syndrome in Humans
}

\author{
Jun Zhang ${ }^{\text {a }}$ Mohammad Kazem Fallahzadeh ${ }^{b}$ Peter A. McCullough ${ }^{a-d}$ \\ ${ }^{a}$ Baylor Heart and Vascular Institute, ${ }^{b}$ Department of Internal Medicine, Baylor University \\ Medical Center, and 'Baylor Jack and Jane Hamilton Heart and Vascular Hospital, Dallas, Tex., and \\ dThe Heart Hospital Baylor Plano, Plano, Tex., USA
}

\section{Key Words}

Acute kidney injury · Cardiorenal syndrome · Iodinated contrast media · Hypertension ·

Neutrophil gelatinase-associated lipocalin $\cdot$ Spontaneously hypertensive rat

\begin{abstract}
Background: Although there are some animal models for biomarkers of contrast-induced acute kidney injury (CI-AKI), for cardiorenal syndrome (CRS) and for acute renal failure, the interplay between CI-AKI and CRS has yet to be evaluated. Insight into the pathogenesis of CRS is urgently needed from animal models in order to foster the discovery and implementation of novel biomarkers for this disease. Specially designed animal models for type 1 and 3 CRS, particularly CI-AKI, have not yet emerged. Summary: We hypothesize that the aging male spontaneously hypertensive rat (SHR) is likely to be a suitable model. The SHR model is able to mimic risk factors for preclinical CRS that appears in the clinical setting, specifically hypertension, age, preexisting damage and dysfunction of the heart and kidney, endothelial dysfunction, increased level of reactive oxygen species, decreased level and bioavailability of nitric oxide (NO), impairment of the L-arginine-NO pathway, and insulin resistance. In the SHR, CI-AKI results in a different profile of AKI biomarkers than is seen with preexisting chronic kidney injury. Key Messages: The SHR model can be used to evaluate the interaction between CI-AKI and CRS type 1 and 3 and to verify neutrophil gelatinase-associated lipocalin (NGAL) as a reliable CI-AKI biomarker for clinical application. Further research is warranted with a large number of aging male SHRs to prove NGAL as a sensitive, specific, highly predictive, early biomarker for CI-AKI.




\section{CardioRenal Medicine}

\begin{tabular}{l|l}
\hline Cardiorenal Med 2017;7:1-10 \\
\hline DOI: 10.1159/000447542 & $\begin{array}{l}\text { @ 2016 S. Karger AG, Basel } \\
\text { www.karger.com/crm }\end{array}$ \\
\hline
\end{tabular}

Zhang et al.: Aging Male Spontaneously Hypertensive Rat as an Animal Model for the Evaluation of the Interplay between CI-AKI and CRS in Humans

\section{Introduction}

Cardiorenal syndrome (CRS) is characterized by different degrees of cardiac and renal dysfunction and the interactions of combined cardiac and renal damages. Five types of CRS have been recognized [1], including an acute group (type 1 CRS and type 3 renocardiac syndrome), a chronic group (type 2 and 4 ) as a counterpart of the acute group, and secondary syndrome (type 5) [1]. Type 1 CRS is defined as an acute worsening of heart function leading to acute kidney injury (AKI) [2-4]. In patients with acute myocardial infarction and acute heart failure who have left or right heart catheterization, the administration of contrast media can contribute to contrast-induced AKI (CI-AKI) [5]. Type 3 CRS is defined as acute worsening of kidney function leading to acute cardiac dysfunction $[1,4]$. Therefore, CI-AKI can potentially contribute to acute cardiac dysfunction in patients with stable cardiac function who undergo elective cardiac catheterization.

CI-AKI is typically defined as an increase in serum creatinine (Cr) of $0.5 \mathrm{mg} / \mathrm{dl}$ or a $25 \%$ increase from the baseline assessed at $48 \mathrm{~h}$ after the angiography procedure [5]. However, serum $\mathrm{Cr}$ is both an indirect and insensitive marker for the evaluation of AKI [5]. The discovery of novel biomarkers of AKI for the early diagnosis of CI-AKI based on a thorough understanding of the pathogenesis of CRS is urgently needed [5]. Although some animal models exist for CI-AKI biomarkers [6], for CRS [7, 8], and for acute renal failure [9], the interaction between CRS and CI-AKI has not yet been evaluated. A new concept called 'preclinical CRS' has recently been introduced. Based on this concept, hypertension in elderly patients acts as a risk factor for subclinical cardiac and renal damage and predisposes these patients to developing CRS type 1 and 3 when they are exposed to contrast media [10].

The aging male spontaneously hypertensive rat (SHR) has been used as a model for evaluating contrast-induced cardiac and renal toxicity [11-16]. We, therefore, hypothesize that in the aging male SHR, preexisting chronic heart failure and hypertension can mimic preclinical CRS in the clinical setting. An interaction between acute cardiorenal and renocardiac syndromes may also exist in the SHR. In this review, we discuss how the aging male SHR can be a suitable animal model for the evaluation of the interaction between CI-AKI and CRS type 1 and 3 .

\section{Similar Risk Factors for CI-AKI Shared by the SHR and Humans with Preclinical CRS}

Table 1 and figure 1 show similar risk factors for CI-AKI, including hypertension, obesity, and age, shared by the SHR [17-23] and humans with preclinical CRS [10, 18, 23-29]. In humans with preclinical CRS, essential hypertension acts as a risk factor for subclinical cardiac and renal damage. Hypertension precedes overt cardiac and renal dysfunction [10] and accounts for $25 \%$ of all causes of chronic kidney disease (CKD) [18]. The SHR is a reliable model of a naturally developing pressure load akin to essential hypertension in humans; therefore, it is generally accepted that the SHR represents an analogue of human essential hypertension $[17,30]$. Severe hypertension occurs in $100 \%$ of SHRs with a systolic blood pressure of $180 \mathrm{~mm} \mathrm{Hg}$ or higher. In the SHR, systolic blood pressure starts to rise at the age of 9 weeks (>150 mm Hg), continues to increase up to week 13, and remains elevated (on average $199.0 \pm 8.1 \mathrm{~mm} \mathrm{Hg}$ ) until 65 weeks [31].

Obese patients with hypertension are at greater risk for developing CKD. A direct link between obesity, hypertension, and the development of CKD has been identified, as evidenced by the development of insulin resistance, endothelial dysfunction (ED), increased levels of circulating proinflammatory cytokines, and renal damage [18]. Elevated levels of circulating free fatty acids and adipokines may contribute to the development of insulin resistance, type 
Zhang et al:: Aging Male Spontaneously Hypertensive Rat as an Animal Model for the Evaluation of the Interplay between CI-AKI and CRS in Humans

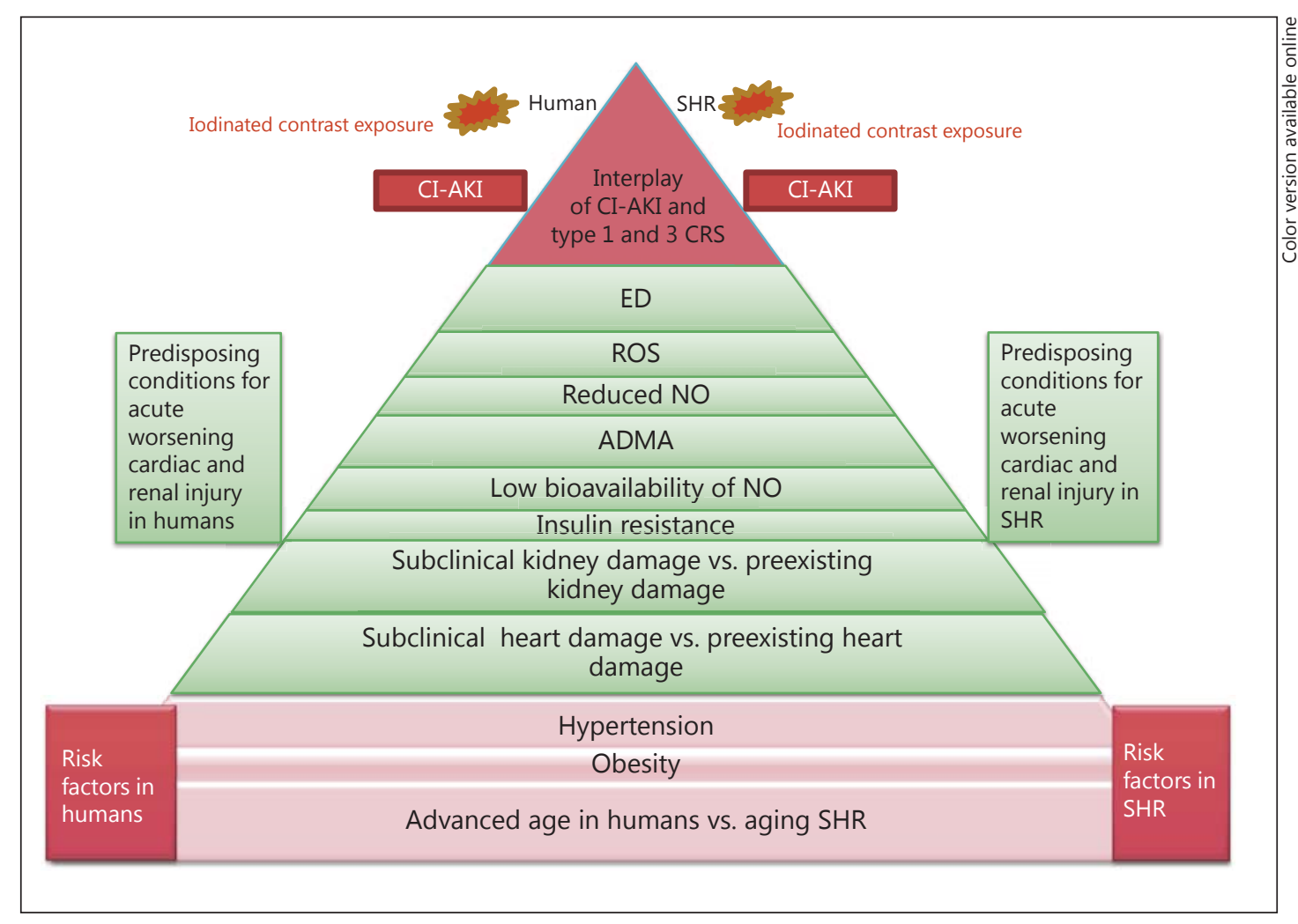

Fig. 1. Comparison of risk factors and predisposing conditions for worsening acute cardiac and renal injury and CI-AKI in SHRs and humans with preclinical CRS.

Table 1. Risk factors, preexisting cardiac and kidney damage, organ interaction between heart and kidney, and predisposing conditions for worsening acute cardiac and renal injury and CI-AKI in SHRs which serve as a model of humans with preclinical CRS

\begin{tabular}{lll}
\hline & SHRs $^{1}$ & Humans $^{2}$ \\
\hline Risk factors & Hypertension & Hypertension \\
& Obesity & Obesity \\
& Old age and male gender & Advanced age and male gender \\
\hline Preexisting & Preexisting cardiac damage & Subclinical cardiac damage \\
damage & Preexisting renal damage & Subclinical renal damage \\
\hline Organ & Cardiac hypertrophy and coronary & LVH and coronary circulation dysfunction \\
interaction & circulation dysfunction leading to renal & leading to renal damage \\
& damage & Renal damage increases cardiovascular risk \\
& Renal glomerulosclerosis is associated with & \\
& acute cardiac injury (myocyte necrosis and & \\
\hline Predisposing & EDoptosis) & \\
conditions & ROS $\uparrow$ & ED $\uparrow$ \\
& ADMA $\uparrow$ & ROS $\uparrow$ \\
& NO $\downarrow$ & ADMA $\uparrow$ \\
& Bioavailability of NO $\downarrow$ & NO $\downarrow$ \\
& L-arginine-NO pathway $\sqrt{ }$ & Bioavailability of NO $\downarrow$ \\
& Insulin resistance $\uparrow$ & L-arginine-NO pathway $\sqrt{ }$ \\
& & Insulin resistance $\uparrow$ \\
\hline
\end{tabular}

${ }^{1}$ References: $14-20,31 .{ }^{2}$ References: $10,24-30$. 
Zhang et al.: Aging Male Spontaneously Hypertensive Rat as an Animal Model for the Evaluation of the Interplay between CI-AKI and CRS in Humans

2 diabetes, and renal injury [18]. Interestingly, when obese SHRs are fed a high-fat diet, they exhibit features similar to those of obese patients with hypertension, such as an increased level of insulin resistance, increased expression of proinflammatory cytokines (IL-1 $\beta, T N F \alpha$, IL-6, and MCP-1), and ED. Therefore, inflammation appears to play a major role in the pathogenesis of CKD in obese patients with hypertension [18].

Aging is one of the main risk factors for the development of CI-AKI in humans. In a prospective study, CI-AKI occurred in 5 of 13 (38.46\%) elderly critically ill patients ( $\geq 65$ years old, $77 \%$ men), while none of 13 younger patients ( $<65$ years old, $100 \%$ men) developed CI-AKI. The mean serum $\mathrm{Cr}$ concentration increased $0.025 \mathrm{mg} / \mathrm{dl} /$ day in older patients for 5 days after contrast exposure, while serum $\mathrm{Cr}$ did not increase in younger patients [32]. In the aging male SHR model for CI-AKI, old male rats $(10,12$, or 14 months old) were more susceptible to developing CI-AKI than younger males (5 and 8 months old) [12]. In 14-month-old SHRs, urinary albumin excretion was markedly increased as a result of dysfunction of the glomerular capillary filter, increased glomerular albumin permeability, and presumably an increased number of more unselective pores in the glomerular barrier [33].

\section{Preexisting Cardiac and Renal Damage in the SHR Closely Resembles That in Humans with Preclinical CRS}

In humans, subclinical cardiac damage is manifested in left ventricular hypertrophy $(\mathrm{LVH})$, as determined by the left ventricular mass index $\left(125 \mathrm{~g} / \mathrm{m}^{2}\right.$ for men and $110 \mathrm{~g} / \mathrm{m}^{2}$ for women) [10], while subclinical renal damage is manifested in decreased levels of estimated glomerular filtration rate (eGFR), increased levels of albuminuria, and increased levels of serum $\mathrm{Cr}$ [10]. LVH is considered a predictor of adverse renal outcome in patients with high cardiovascular risk [24]. Augmented LV mass index and higher LVH rates are correlated with an increase in urinary albumin excretion [25]. Further, LVH is accompanied by a reduction of renal function in hypertensive patients [26].

In the SHR, LVH increases with age, especially at 30 weeks [31]. Interestingly, older SHRs have higher rates of myocardial infarction, cardiac scar formation and arteriolar nephrosclerosis, renal injury, and proteinuria [17]. In the SHR, the activity of the renin-angiotensin system is increased, as determined by the activity of the juxtaglomerular cell granules and as demonstrated by a histological finding of degranulation and atrophy in the juxtaglomerular apparatus [21]. Increases in urinary protein and albumin excretion are accompanied by glomerulosclerosis and arteriolar sclerotic changes in the juxtamedullary and deep cortical nephrons. These areas of the kidney are likely to be less protected in the SHR [31]. The interaction between preexisting cardiac and renal damage is also observed in SHRs. This interaction is evident in SHRs exposed to contrast. These SHRs show an acute worsening of cardiac damage (apoptosis and necrosis of cardiomyocytes) contributing to CI-AKI, as demonstrated by glomerular necrosis and sclerosis, tubular cell apoptosis and necrosis, interstitial lymphocytic infiltration, and apoptosis of endothelial cells and smooth muscle cells in small vessels of the heart and kidney $[12,15]$.

\section{Similar Pathogenesis of ED and Asymmetric Dimethylarginine in the SHR and Humans with Preclinical CRS}

In the SHR, aging is a significant factor affecting vascular ED [19]. ED exists in aged SHRs (older than 25 weeks) but not in young SHRs [19]. ED precedes renal injury and exacerbates renal injury under certain conditions (e.g. high-fat diet) in which reactive oxygen 
Zhang et al.: Aging Male Spontaneously Hypertensive Rat as an Animal Model for the Evaluation of the Interplay between CI-AKI and CRS in Humans

species (ROS) are upregulated [18]. Furthermore, ED seems to be the consequence rather than a primary cause of high blood pressure $[19,22]$. ED is also associated with reduced endothelial nitric oxide synthase (eNOS) expression and NO production in the SHR [22]. Vasoconstrictor factors, such as endothelins, angiotensin II, prostaglandin $\mathrm{H}_{2}$, and thromboxane $\mathrm{A}_{2}$, are likely to play a role in the 'vicious cycle' leading to cardiac and renal damage [22]. In essential hypertension patients, vascular ED occurs during the aging process and is accompanied by a progressive reduction of NO bioavailability [34, 35]. ROS-mediated cellular injury and renal parenchymal hypoxic-toxic injury are closely related to ED in patients with CI-AKI [36]. In hypertensive patients, endothelium-dependent vasodilation in the kidney is impaired by aging, and the L-arginine-NO pathway involving impaired arginine transport participates in the regulation of renal hemodynamics and renal excretory function [23]. In addition, ED has been reported to result in a subsequent decline of the eGFR in hypertensive patients [37].

Asymmetric dimethylarginine (ADMA) inhibits NOS production of NO by competing with its substrate, L-arginine. Plasma levels of ADMA are significantly higher in SHRs at 4 weeks (prehypertensive stage), 12 weeks (hypertensive stage), and 24 weeks (hypertensive endorgan damage stage) [34]. A significantly higher concentration of plasma ADMA also exists in aging (16-month-old) male SHRs [38]. These findings indicate that a reduced NO bioavailability is associated with hypertension and end-organ damage [36] and that ADMA is a risk factor for ED [38]. The information obtained from SHRs suggests a low bioavailability of NO and impairment of the L-arginine-NO pathway in humans [23].

If SHRs are fed a high-fat diet for 10 weeks, they develop insulin resistance [18]. High insulin levels can induce renal hemodynamic changes, glomerular hypertrophy, and mesangial cell proliferation [18]. Information obtained from the SHR model supports the idea that insulin resistance is increased in hypertensive patients [18]. In hypertensive patients, ADMA plasma levels and insulin resistance are significantly higher, and acetylcholine-stimulated forearm blood flow is significantly reduced, demonstrating the role of ADMA and insulin resistance in inducing ED [27]. Furthermore, plasma levels of ADMA are likely to be dynamically regulated and correlated with some measure of NO bioavailability [27].

\section{Neutrophil Gelatinase-Associated Lipocalin for CI-AKI in the SHR Is Consistent with That in Patients with CI-AKI}

Table 2 compares neutrophil gelatinase-associated lipocalin (NGAL) detected in SHRs and humans with CI-AKI. In SHRs with CI-AKI, the area under the receiver operating characteristic curve (AUROC) value of NGAL is 0.73 , which is accepted as a value of failure [6]. In contrast, in humans with CI-AKI, 4 of 8 studies showed an excellent value (0.93-1.0) [39-42], 2 of 8 studies showed a good value of NGAL (0.83-0.84) [43,44], and 2 of 8 studies showed a poor value of NGAL $(0.63-0.68)[29,45]$. In CKD patients undergoing elective coronary angiography with contrast, postprocedural NGAL increases from baseline in each stage of CKD [46]. In patients undergoing open heart surgery with AKI, urine catalytic iron levels are highly correlated with urine NGAL levels [47]. The difference in AUROC values of NGAL between SHRs and humans may be due to the young age of SHRs (5 months old) in an animal model used by Rouse et al. [6]; therefore, the level of NGAL may not yet reflect severely worsening AKI. In contrast, older SHRs, at 14-16 months of age, may have higher levels of NGAL due to the loss of a renal functional reserve and contrast-induced acute deterioration of renal function. Therefore, we propose that older SHRs may be a better model for the evaluation of the interaction between CRS and CI-AKI. In addition, the appearance of NGAL occurs earlier in humans $(2,4,6,8$, and $24 \mathrm{~h}$ after contrast administration) than in SHRs (72 h). 
Zhang et al.: Aging Male Spontaneously Hypertensive Rat as an Animal Model for the Evaluation of the Interplay between CI-AKI and CRS in Humans

Table 2. Comparison of the NGAL biomarker in SHRs and humans

\begin{tabular}{|c|c|c|c|}
\hline Study [ref.], year & SHRs or humans & AUROC $^{1}$ & Note \\
\hline $\begin{array}{l}\text { Rouse et al. [6], } \\
2014\end{array}$ & SHRs & 0.73 & $\begin{array}{l}5 \text { SHRs; urinary NGAL, } 72 \mathrm{~h} \text { after exposure to contrast } \\
\text { medium iohexol }\end{array}$ \\
\hline $\begin{array}{l}\text { Liebetrau et al. } \\
\text { [39], } 2014\end{array}$ & Humans & 0.94 & $\begin{array}{l}14 \text { of } 128 \text { patients undergoing PCI; urinary NGAL, } 1 \text { day } \\
\text { after PCI }\end{array}$ \\
\hline $\begin{array}{l}\text { Tasanarong et al. } \\
{[43], 2013}\end{array}$ & Humans & 0.84 & $\begin{array}{l}16 \text { of } 130 \text { CKD patients undergoing elective coronary } \\
\text { procedures; urinary NGAL, at } 6 \mathrm{~h}\end{array}$ \\
\hline $\begin{array}{l}\text { Filiopoulos et al. } \\
{[40], 2013}\end{array}$ & Humans & 1.00 & $\begin{array}{l}4 \text { of } 47 \text { patients undergoing elective contrast-enhanced } \\
\text { CT; plasma NGAL, } 6 \mathrm{~h} \text { after contrast administration }\end{array}$ \\
\hline $\begin{array}{l}\text { Lacquantiti et al. } \\
{[41], 2013}\end{array}$ & Humans & 0.99 & $\begin{array}{l}23 \text { of } 60 \text { patients receiving iomeprol; urinary NGAL } \\
(0.992) \text {, serum NGAL }(0.995), 8 \mathrm{~h} \text { after iomeprol } \\
\text { administration }\end{array}$ \\
\hline $\begin{array}{l}\text { Alvelos et al. [42], } \\
2011\end{array}$ & Humans & 0.93 & $\begin{array}{l}14 \text { of } 119 \text { acute HF patients with developing type } 1 \text { CRS } \\
\text { within } 48-72 \text { h; plasma NGAL }\end{array}$ \\
\hline $\begin{array}{l}\text { Valette et al. [44], } \\
2013\end{array}$ & Humans & 0.83 & $\begin{array}{l}98 \text { patients with sepsis or previous AKI, } 30 \text { developed } \\
\text { CI-AKI; plasma NGAL } 0.83 \text { or } 0.86,6 \text { or } 24 \text { h after } \\
\text { contrast administration, respectively; however, the } \\
\text { discriminative value of plasma NGAL to predict CI-AKI } \\
\text { and mortality was poor }\end{array}$ \\
\hline $\begin{array}{l}\text { Okumura et al. } \\
{[29], 2014}\end{array}$ & Humans & 0.63 & $\begin{array}{l}58 \text { of } 100 \text { CKD patients undergoing angiographic } \\
\text { procedures and with deterioration of eGFR; urinary } \\
\text { NGAL, } 2 \text { h after the procedure }\end{array}$ \\
\hline $\begin{array}{l}\text { Liu et al. [47], } \\
2012\end{array}$ & Humans & 0.66 & $\begin{array}{l}39 \text { of } 311 \text { patients undergoing diagnostic cardiac } \\
\text { angiography or PCI; plasma NGAL, } 4 \mathrm{~h} \text { after the } \\
\text { procedures }\end{array}$ \\
\hline
\end{tabular}

$\mathrm{CT}=$ Computed tomography; $\mathrm{HF}=$ heart failure; $\mathrm{PCI}=$ percutaneous coronary interventions. ${ }^{1}$ All values are indicated by the AUROC; a rough guide for classifying the accuracy of a diagnostic test is the traditional academic point system: AUROC $0.90-1.0=$ excellent; $0.80-0.90=$ good; $0.70-0.80=$ fair; $0.60-0.70=$ poor, and $0.50-0.60=$ fail.

Interestingly, NGAL induces cardiomyocyte apoptosis via a pathway of elevated intracellular iron levels and Bax translocation [48]. This is consistent with findings in the SHR model with CI-AKI, which showed that cardiomyocyte apoptosis is associated with increased NGAL as well as increased Bax immunoreactivity $[3,12]$. Thus, NGAL is likely to act as a link between CI-AKI and acute heart failure in type 3 CRS. In addition, NGAL is actively upregulated and secreted in response to free catalytic iron that is both intracellular and extracellular as a result of cell damage and release from binding proteins in the electron transport chain, mitochondria, and structure proteins. Constitutive upregulation of NGAL production can mitigate chronic oxidative stress catalyzed by intra- and extracellular catalytic iron [49]. Interestingly, iron chelators like deferiprone were shown to protect kidneys against iron-induced oxidative damage in a clinical trial of CI-AKI [5].

\section{The Concept of a Renal Functional Reserve: Insights from the Aging Male SHR Model}

Figure 2 presents our proposed concept of a renal functional reserve in the SHR model based on current information [11-16, 31, 34, 36, 46, 50-52]. In the proposed concept, we made 3 scenarios based on the gradual progress of preexisting renal damage: (1) decline 
Zhang et al.: Aging Male Spontaneously Hypertensive Rat as an Animal Model for the Evaluation of the Interplay between CI-AKI and CRS in Humans

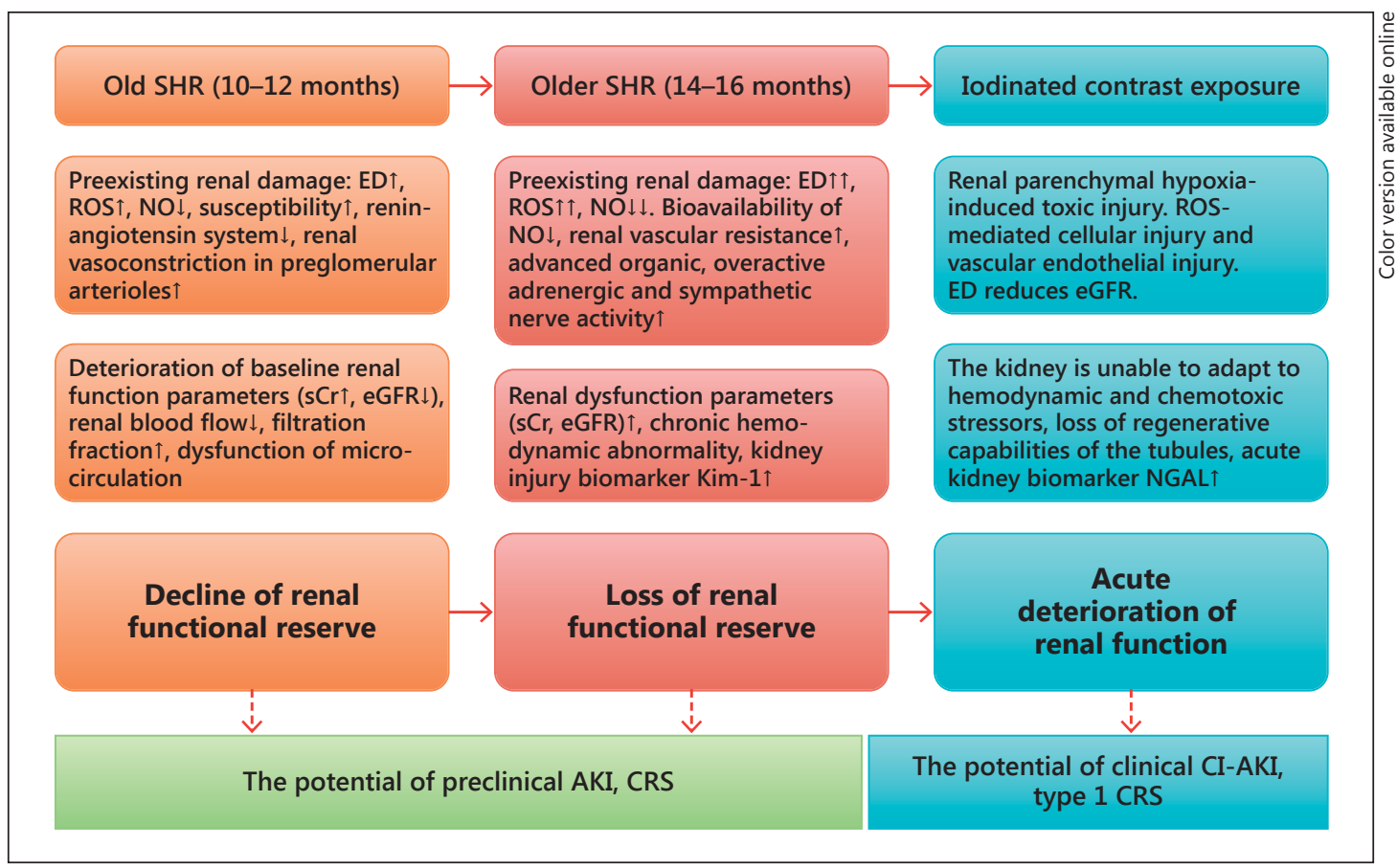

Fig. 2. Renal functional reserve and clinical relevance: insights from an aging male SHR model.

of a renal functional reserve at the age of 10-12 months; (2) loss of a renal functional reserve at the age of 14-16 months, and (3) acute deterioration of renal function (acute renal failure) after iodinated contrast exposure. The first and second scenarios represent background kidney injury before contrast exposure. Mild contrast exposure in SHRs results in kidney injury but not total loss of renal function. Therefore, SHRs with mild contrast exposure can serve as a model for subclinical CI-AKI [46]. On the other hand, moderate or heavy contrast exposure in SHRs results in complete loss of renal function. Therefore, SHRs with moderate-to-heavy exposure can serve as an animal model for clinically overt CI-AKI.

\section{Can Characteristics of the SHR Translate to Patients with CRS Type 1 and 3?}

Some may argue that characteristics of the SHR may not translate to patients with CRS type 1 and 3 in terms of sympathetic nervous system (SNS) activation and renin status. The incidence of hypertension is believed to increase with age and to be related to age-associated SNS changes [53]. In older hypertensive subjects, the plasma norepinephrine metabolic clearance rate is increased, and systemic SNS activity tends to be increased [54]. An increase in SNS activity has been reported in the initiation of hypertension in human essential hypertension $[54,55]$. Likewise, in male SHRs, increased SNS activity is related to the development of hypertension [56-59]. In the SHR, the activity of the renin-angiotensin system is also increased [21]. SHRs (13 and 35 weeks old) with established hypertension develop a persistent high-renin state which may be similar to that observed in $9-16 \%$ of essential hypertensive patients [60]. 


\section{CardioRenal Medicine}

\begin{tabular}{l|l}
\hline Cardiorenal Med 2017;7:1-10 \\
\hline DOI: 10.1159/000447542 & $\begin{array}{l}\text { ( ) 2016 S. Karger AG, Basel } \\
\text { www.karger.com/crm }\end{array}$ \\
\hline
\end{tabular}

Zhang et al.: Aging Male Spontaneously Hypertensive Rat as an Animal Model for the Evaluation of the Interplay between CI-AKI and CRS in Humans

\section{Conclusions}

The aging male SHR develops spontaneous cardiac and renal damage that progresses with age, increasing the susceptibility to the cardiorenal damaging effects of contrast media. Thus, the aging male SHR provides a laboratory tool for the evaluation of the interaction between CI-AKI and CRS type 1 and 3 and the discovery of the novel biomarker NGAL for CI-AKI.

\section{Acknowledgments}

The authors would like to acknowledge Wendy Hegefeld, PhD, at Baylor Scott and White Health for her help and guidance in manuscript preparation.

\section{Statement of Ethics}

This work did not involve human subjects or animals and was exempt from review by Baylor Institutional Review Board.

\section{Disclosure Statement}

There are no conflicts of interest to disclose.

\section{References}

1 Ronco C, Lullo LD: Cardiorenal syndrome. Heart Failure Clin 2014;10:251-280.

2 Ronco C, Cicoira M, McCullough PA: Cardiorenal syndrome type 1: pathophysiological crosstalk leading to combined heart and kidney dysfunction in the setting of acutely decompensated heart failure. J Am Coll Cardiol 2012;60:1031-1042.

3 Palazzuoli A, McCullough PA, Ronco C, Nuti R: Kidney disease in heart failure: the importance of novel biomarkers for type 1 cardio-renal syndrome detection. Intern Emerg Med 2015;10:543-554.

4 Clementi A, Virzi GM, Brocca A, de Cal M, Pastori S, Clementi M, Granata A, Vescovo G, Ronco C: Advances in the pathogenesis of cardiorenal syndrome type 3. Oxid Med Cell Longev 2015, DOI: 10.1155/2015/148082.

5 McCullough PA: Radiocontrast-induced acute kidney injury. Nephron Physiol 2008;109:61-72.

6 Rouse R, Stewart SR, Thompson KL, Zhang J: Kidney injury biomarkers in hypertensive, diabetic, and nephropathy rat models with contrast medium. Toxicol Pathol 2013;41:662-680.

7 Bongartz LG, Braam B, Gaillard CA, Cramer MJ, Goldschmeding R, Verhaar MC, Doevendans PA, Joles JA: Target organ cross talk in cardiorenal syndrome: animal models. Am J Physiol Renal Physiol 2012;303:F1253-F1263.

8 Szymanski MK, de Boer RA, Navis GJ, van Gilst WH, Hillege HL: Animal models of cardiorenal syndrome: a review. Heart Fail Rev 2012;17:411-420.

9 Singn AP, Muthuraman A, Jaggi AS, Singh N, Grover K, Dhawan R: Animal models of acute renal failure. Pharmacol Rep 2012;64:31-44.

10 Tsioufis C, Tsiachris D, Kasiakogias A, Dimitriadis K, Petras D, Goumenos D, Siamopoulos K, Stefanadis C: Preclinical cardiorenal syndrome interrelationships in essential hypertension. Cardiorenal Med 2013;3: 38-47.

11 Duarte CG, Ellis S: Renal effects of a radiocontrast agent in aging spontaneously hypertensive rats. Contrib Nephrol 1990;83:222-228.

12 Duarte CG, Zhang J, Ellis S: The SHR as a small animal model for radiocontrast renal failure. Relation of nephrotoxicity to animal's age, gender, strain, and dose of radiocontrast. Ren Fail 1997;19:723-743.

13 Duarte CG, Zhang J, Ellis S: Effects of radiocontrast and endothelin administration on systolic blood pressure and renal damage in male spontaneously hypertensive and Wistar Kyoto rats with phentolamine-induced adrenergic blockade. Invest Radiol 1998;33:104-112.

14 Duarte CG, Zhang J, Ellis S: Effects of radiocontrast, mannitol, and endothelin on blood pressure and renal damage in the aging male spontaneously hypertensive rat. Invest Radiol 1999;34:455-462.

15 Zhang J, Duarte CG, Ellis S: Contrast medium- and mannitol-induced apoptosis in heart and kidney of spontaneously hypertensive rats. Toxicol Pathol 1999;27:427-435. 
Zhang et al.: Aging Male Spontaneously Hypertensive Rat as an Animal Model for the

Evaluation of the Interplay between CI-AKI and CRS in Humans

16 Duarte CG, Zhang J, Ellis S: Review of studies establishing the aging male spontaneously hypertensive rat as a detector and quantifier of the kidney toxicity of radiocontrast media and other chemicals. Invest Radiol 2001; 36:56-63.

17 Okamoto K, Tabei R, Yamori Y, Ooshima A: Spontaneously hypertensive rat as a useful model for hypertension research. Jikken Dobutsu 1973;22(suppl):289-298.

18 Knight SF, Quigley JE, Yuan J, Roy S, Elmarakby A, Imig JD: Endothelial dysfunction and the development of renal injury in spontaneously hypertensive rats fed a high-fat diet. Hypertension 2008;51:352-359.

19 Bernatova I, Conde MV, Kopincova J, González MC, Puzserova A, Arribas SM: Endothelial dysfunction in spontaneously hypertensive rats: focus on methodological aspects. J Hypertens 2009;27(suppl 6):S27-S31.

20 Okamoto K, Abe M, Haneda T: Effect of regression of cardiac hypertrophy on ischemic myocardial damage in spontaneously hypertensive rats. Jpn Circ J 1993;57:147-160.

21 Haga M, Sokabe H, Okamato K: Juxtaglomerular cell granules in the spontaneously hypertensive rat. Jpn Circ J 1966;30:1479-1482.

22 Vappaatalo H, Mervaala E, Nurminen ML: Role of endothelium and nitric oxide in experimental hypertension. Physiol Res 2000;49:1-10.

23 Mattei P, Virdis A, Ghiadoni L, Taddei S, Salvetti A: Endothelial function in hypertension. J Nephrol 1997;10: 192-197.

24 Tsioufis C, Kokkinos P, Macmanus C, Thomopoulos C, Faselis C, Doumas M, Stefanadis C, Papademetriou V: Left ventricular hypertrophy as a determinant of renal outcome in patients with high cardiovascular risk. J Hypertens 2010;28:2299-2308.

25 Andrikou E, Tsioufis C, Dimitriadis K, Flessas D, Chatzistamatou V, Grassos C, Papavasilion M, Papadopoulos D, Stefanadis C: Parallel deterioration of albuminuria, arterial stiffness and left ventricular mass in essential hypertension: integrating target organ damage. Nephron Clin Pract 2011;119:c27-c34.

26 Cerasola G, Nardi E, Mulè G, Palermo A, Cusimano P, Guarnet M, Arsena R, Giammarresi G, Carola Foraci A, Cottone S: Left ventricular mass in hypertensive patients with mild-moderate reduction of renal function. Nephrology (Carlton) 2010;15:203-210.

27 Perticone F, Sciacqua A, Maio R, Perticone M, Galiano Leone G, Bruni R, di Cello S, Pascale A, Talarico G, Greco L, Andrreozz F, Sesti G: Endothelial dysfunction, ADMA and insulin resistance in essential hypertension. Int J Cardiol 2010;142:236-241.

28 Félétou M, Vanhoutte PM: Endothelial dysfunction: a multifaceted disorder (The Wiggers Award Lecture). Am J Physiol Heart Circ Physiol 2006;291:H985-H1002.

29 Okumura N, Hyashi M, Ishii H, Yoshikawa D, Yasuda Y, Goto M, Matsuo S, Oiso Y, Murohara T: Novel preprocedural and acute-phase postprocedural predictive factors for contrast-induced kidney injury in CKD patients. Int J Cardiol 2014;172:e293-e296.

30 Taddei S, Virdis A, Ghiadoni L, Salvetti G, Bernini G, Magagna A, Salvetti A: Age-related reduction of NO availability and oxidative stress in humans. Hypertension 2001;38:274-279.

31 Feld LG, van Liew JB, Galaske RG, Boylan JW: Selectivity of renal injury and proteinuria in the spontaneously hypertensive rat. Kidney Int 1977;12:332-343.

32 Palli E, Makris D, Papanikolaou J, Garoufalis G, Zakynthinos E: Contrast-induced nephropathy in aged critically ill patients. Oxid Med Cell Longev 2014;2014:756469.

33 Bakoush O, Tencer J, Torffvit O, Tenstad O, Skogvall I, Rippe B: Increased glomerular albumin permeability in old spontaneously hypertensive rats. Nephrol Dial Transplant 2004;19:1724-1731.

34 Hsu CN, Huang LT, Lau CY, Tain YL: The combined ratios of L-arginine and asymmetric dimethylarginine as biomarkers in spontaneously hypertensive rats. Transl Res 2012;159:90-98.

35 Herrera MD, Mingorance C, Rodriguez-Rodriguez R, de Sotomayor MA: Endothelial dysfunction and aging: an update. Ageing Res Rev 2010;9:142-152.

36 Perticone F, Mario R, Perticone M, Sciacqua A, Shehaj E, Naccarato P, Sesti G: Endothelial dysfunction and subsequent decline in glomerular filtration rate in hypertensive patients. Circulation 2010;122:379-384.

37 Pisani A, Riccio E, Andreucci MJ, Faga T, Ashour M, di Nuzzi A, Mancini A, Sabbatini M: Role of reactive oxygen species in pathogenesis of radiocontrast-induced nephropathy. Biomed Res Int 2013;2013:868321.

38 Raimondi L, Lodovici M, Visioli F, Sartiani L, Cioni L, Alfarano C, Banchelli G, Pirisino R, Cecchi E, Cerbai E, Muqelli A: N-3 polyunsaturated fatty acids supplementation decreases asymmetric dimethyl arginine and arachidonate accumulation in aging spontaneously hypertensive rats. Eur J Nutr 2005;44:3237-3333.

39 Liebetrau C, Gaede L, Blumenstein J, Rixe J, Teichert O, Willmer M, Weber M, Rolf A, Möllmann H, Hamm C, Nef $\mathrm{H}$ : Neutrophil gelatinase-associated lipocalin (NGAL) for the early detection of contrast-induced nephropathy after percutaneous coronary intervention. Scand J Clin Lab Invest 2014;74:81-88.

40 Filiopoulos V, Biblaki D, Lazarou D, Chrisis D, Fatourou M, Lafoyianni S, Vlassopoulos D: Plasma neutrophil gelatinase-associated lipocalin (NGAL) as an early predictive marker of contrast-induced nephropathy in hospitalized patients undergoing computed tomography. Clin Kidney J 2013;6:578-583.

41 Lacquantiti A, Buemi F, Lupica R, Giardina C, Murè G, Arena A, Visalli C, Baldari S, Aloisi C, Buemi M: Can neutrophil gelatinase-associated lipocalin help depict early contrast material-induced nephropathy? Radiology 2013;267:86-93.

42 Alvelos M, Pimentel R, Pinho E, Gomes A, Lourenco P, Teles MJ, Almeida P, Guimarães JT, Bettencourt P: Neutrophil gelatinase-associated lipocalin in the diagnosis of type 1 cardio-renal syndrome in the general ward. Clin J Am Soc Nephrol 2011;6:476-481. 
43 Tasanarong A, Hutayanon P, Piyaotai D: Urinary neutrophil gelatinase-associated lipocalin predicts the severity of contrast-induced acute kidney injury in chronic kidney disease patients undergoing elective coronary procedures. BMC Nephrol 2013;14:270.

44 Valette X, Savary B, Nowoczyn M, Daaubin C, Pottier V, Terzi N, Sequin A, Fradin S, Charbonneau P, Hanouz JL, du Cheyron D: Accuracy of plasma neutrophil gelatinase-associated lipocalin in the early diagnosis of contrastinduced acute kidney injury in critical illness. Intensive Care Med 2013;39:857-865.

45 Liu XL, Wang ZJ, Yang Q, Yu M, Shen H, Nie B, Han HY, Gao F, Zhou YJ: Plasma neutrophil-gelatinase-associated lipocalin and cystatin $\mathrm{C}$ could early diagnose contrast-induced acute kidney injury in patients with renal insufficiency undergoing an elective percutaneous coronary intervention. Chin Med J (Engl) 2012;125:1051-1056.

46 Akrawinthawong K, Ricci J, Cannon L, Dixon S, Kupfer K, Stivers D, Alexander P, David S, McCullough PA: Subclinical and clinical contrast-induced acute kidney injury: data from a novel blood marker for determining the risk of developing contrast-induced nephropathy (ENCINO), a prospective study. Ren Fail 2015;37:187191.

47 Akrawinthawong K, Shaw MK, Kachner J, Apostolov EO, Basnakian AG, Shah S, Tilak J, McCullough PA: Urine catalytic iron and neutrophil gelatinase-associated lipocalin as comparison early markers of acute kidney injury after cardiac surgery: a prospective pilot study. Cardiorenal Med 2013;3:7-16.

48 Xu G, Ahn JH, Chang SY, Eguchi M, Ogier A, Han SJ, Park YS, Shim CY, Jang YS, Yang B, Xu A, Wang Y, Sweeney G: Lipocalin-2 induces cardiomyocyte apoptosis by increasing intracellular iron accumulation. J Biol Chem 2012;287:4808-4817.

49 McCullough PA, Williams FJ, Stivers DN, Cannon L, Dixon S, Alexander P, Runyan D, David S: Neutrophil gelatinase-associated lipocalin: a novel marker of contrast nephropathy risk. Am J Nephrol 2012;35:509-514.

50 Trippodo NC, Frohlich ED: Similarities of genetic (spontaneous) hypertension. Man and rat. Circ Res 1981;48: 309-319.

51 Heyman SN, Rosen S, Khamaisi M, Idèe J-M, Rosenberg C: Reactive oxygen species and the pathogenesis of radiocontrast-induced nephropathy. Invest Radiol 2010;45:188-195.

52 Scoditti E, Massaro M, Montinari MR: Endothelial safety of radiological contrast media: why being concerned. Vascul Pharmacol 2013;58:48-53.

53 Tuck ML: The sympathetic nervous system in essential hypertension. Am Heart J 1986;112:877-886.

54 Supiano MA, Hogikyan RV, Sidani MA, Galecki AT, Krueger JL: Sympathetic nervous system activity and $\alpha$-adrenergic responsiveness in older hypertensive humans. Am J Physiol 1999;276:E519-E528.

55 Matsukawa T, Mano T, Gotoh E, Ishii M: Elevated sympathetic nerve activity in patients with accelerated essential hypertension. J Clin Invest 1993;92:25-28.

56 Gattone VH, Venan AP, Overhage JM, Severs WB: Developing renal innervations in spontaneously hypertensive rat: evidence for a role of the sympathetic nervous system in renal damage. J Hypertension 1990;8: 423-428.

57 Okamoto K, Nosaka S, Yamori Y, Matsumoto M: Participation of neural factor in the pathogenesis of hypertension in the spontaneously hypertensive rat. Jpn Heart J 1967;8:168-180.

58 Wintermitz SR, Katholi RE, Oparil S: Role of the renal sympathetic nerves in the development and maintenance of hypertension in the spontaneously hypertensive rat. J Clin Invest 1980;66:971-978.

59 Judy WV, Watanabe AM, Herry DR, et al: Sympathetic nerve activity: role in regulation of blood pressure in the spontaneously hypertensive rat. Circ Res 1976;38(6 suppl 2):21-29.

60 Bagby SP, McDonald WJ, Mass RD: Serial renin-angiotensin studies in spontaneously hypertensive and WistarKyoto normotensive rats. Transition from normal- to high-renin status during the established phase of spontaneous hypertension. Hypertension 1979;1:347-354. 